\title{
Abi-2, a novel SH3-containing protein interacts with the c-Abl tyrosine kinase and modulates $\mathrm{c}-\mathrm{Abl}$ transforming activity
}

\author{
Zonghan Dai and Ann Marie Pendergast ${ }^{1}$ \\ Department of Pharmacology, Duke University Medical Center, Durham, North Carolina 27710 USA
}

\begin{abstract}
A protein has been identified that interacts specifically with both the Src homologous 3 (SH3) domain and carboxy-terminal sequences of the c-Abl tyrosine kinase. The cDNA encoding the Abl interactor protein (Abi-2), was isolated from a human lymphocyte library using the yeast two-hybrid system with the Abl SH3 domain as bait. Abi-2 binds to c-Abl in vitro and in vivo. Abi-2 is a novel protein that contains an $\mathrm{SH} 3$ domain and proline-rich sequences critical for binding to c-Abl. A basic region in the amino terminus of Abi-2 is homologous to the DNA-binding sequence of homeo-domain proteins. We show that Abi-2 is a substrate for the c-Abl tyrosine kinase. Expression of an Abi-2 mutant protein that lacks sequences required for binding to the Abl SH3 domain but retains binding to the Abl carboxyl terminus activates the transforming capacity of c-Abl. The properties of Abi-2 are consistent with a dual role as regulator and potential effector of the c-Abl protein and suggest that Abi-2 may function as a tumor suppressor in mammalian cells.
\end{abstract}

[Key Words: Abl substrate; signaling; homeo-domain homology; tumor suppressor; cancer]

Received July 27, 1995; revised version accepted September 14, 1995.

The c-Abl protein, originally identified as the cellular homolog of the v-abl oncogene product of Abelson murine leukemia virus (A-MuLV) (Goff et al. 1980; Wang et al. 1984), is a tyrosine kinase of unknown function. Biochemical data suggest that c-Abl may regulate signal transduction events in the cytoplasm and processes in the nucleus. $\mathrm{c}-\mathrm{Abl}$ is found primarily in the nucleus (Van Etten et al. 1989), but it is also found in association with the plasma membrane and bound to actin filaments in the cytoplasm (Van Etten et al. 1989; Van Etten et al. 1994). In several nontransfected hematopoietic cells, $\mathrm{c}-\mathrm{Abl}$ is predominantly localized to the cytoplasm with some nuclear staining (Wetzler et al. 1993).

The c-Abl protein has a complex structure that includes several domains common to proteins implicated in signal transduction pathways. Among these domains are the noncatalytic Src homology 2 and 3 (SH2 and $\mathrm{SH} 3$ ) domains and the tyrosine kinase (SH1) domain. $\mathrm{SH} 2$ and SH3 domains are modular components present in a large number of proteins (Pawson 1995). These domains are critical in the formation of stable signaling protein complexes (Pawson 1995), and have also been shown to regulate protein function (Feller et al. 1994b; Cohen et al. 1995; Pawson 1995). The SH3 domain suppresses the intrinsic transforming activity of c-Abl in vivo (Franz et al. 1989; Jackson and Baltimore 1989) while the SH2 domain is required for the transforming function of acti-

\footnotetext{
${ }^{1}$ Corresponding author.
}

vated $a b l$ genes (Mayer et al. 1992; Mayer and Baltimore 1994). The unique carboxy-terminal region of c-Abl, which is encoded by a single exon, contains several functional and structural domains that include a nuclear localization signal (NLS) (Van Etten et al. 1989), prolinerich sequences that have the potential to bind to SH3domain-containing proteins (Feller et al. 1994a,b; Ren et al. 1994), a DNA-binding domain (Kipreos and Wang 1992), and an actin-binding domain (McWhirter and Wang 1993; Van Etten et al. 1994). Several serine/threonine residues within the carboxy-terminal exon are phosphorylated by the cdc2 kinase (Kipreos and Wang 1990) and by protein kinase C (Pendergast et al. 1987). The presence of multiple structural and functional domains within the c-Abl tyrosine kinase and its localization to cytoplasmic and nuclear cellular compartments suggest a potential role for $\mathrm{c}$-Abl in the regulation of transcription, DNA replication or cell cycle progression, as well as in the control of signaling events in the cytoplasm.

The tyrosine kinase activity of $\mathrm{c}-\mathrm{Abl}$ is tightly regulated in vivo (Pendergast et al. 1991a; Mayer and Baltimore 1994). Overexpression of c-Abl at levels 5- to 10fold over the endogenous c-Abl protein does not lead to cell transformation but causes growth arrest (Jackson and Baltimore 1989; Jackson et al. 1993; Sawyers et al. 1994). In contrast, structurally altered forms of Abl cause cell transformation and exhibit elevated tyrosine kinase activity when expressed at similar levels (Franz et al. 1989; Jackson and Baltimore 1989; Muller et al. 1991). 
Activation of the oncogenic potential of $\mathrm{c}-\mathrm{Abl}$ has been shown to occur as a consequence of structural alterations in the amino- or carboxy-terminal sequences (for review, see Wang 1993). Three naturally occurring c-ablderived oncogenes have been identified. They are the $\mathrm{v}-a b l$ oncogene of A-MuLV (Goff et al. 1980), the v-abl oncogene of the Hardy-Zuckerman-2 feline sarcoma virus (HZ2-FSV) (Bergold et al. 1987), and the bcr-abl chimeric oncogene of Philadelphia chromosome-positive human leukemias (for review, see Kurzrock et al. 1988). Interestingly, the oncogenic activity of the v- $a b l$ oncogene of A-MuLV is a result of the deletion of the Abl SH3 domain and fusion with gag sequences (Franz et al. 1989; Jackson and Baltimore 1989; Muller et al. 1991) while activation of the v- $a b 1$ oncogene of HZ2-FSV is associated with deletion of Abl carboxy-terminal sequences and fusion with viral sequences with retention of the $\mathrm{Abl}$ SH3 domain (Bergold et al. 1987). Mutants of c-Abl with deletions or alterations in the $\mathrm{SH} 3$ and carboxy-terminal sequences have also been generated experimentally that exhibit increased transforming activity (Franz et al. 1989; Jackson and Baltimore 1989; Goga et al. 1993; Mayer and Baltimore 1994). The transforming Abl proteins are constitutively active tyrosine kinases and are primarily localized in the cytoplasm.

Several possible mechanisms have been suggested for the inhibition of the c-Abl tyrosine kinase. The inhibitory effect of the Abl SH3 domain is extremely position sensitive (Mayer and Baltimore 1994). These results, together with the data described above, suggest that in addition to the SH3 domain, other regions of c-Abl may be required for repression. Two potential mechanisms have been proposed. First, it is possible that the $\mathrm{SH} 3$ domain functions in cis by binding to another region of $\mathrm{Abl}$ and effectively locking the protein in an inactive conformation. As mutations in both the $\mathrm{SH} 3$ and carboxy-terminal sequences result in release of the $\mathrm{c}-\mathrm{Abl}$ protein from inhibition, it is possible that cis-inhibitory sequences are present in the carboxy-terminal domain. The Abl SH3 domain binds to proline-rich sequences (Cicchetti et al. 1992; Ren et al. 1993). Several proline-rich sequences have been identified in the carboxy-terminal domain of c-Abl (Ren et al. 1994). However, no appreciable binding has been detected between the Abl carboxy-terminal sequences and the Abl SH3 domain (Ren et al. 1994; Z. Dai and A.M. Pendergast, unpubl.). A second model consistent with the available data suggests that the c-Abl protein is negatively regulated by a trans-acting cellular inhibitor that exerts its effects by interacting with the $\mathrm{Abl}$ $\mathrm{SH} 3$ domain and a second region of the Abl protein (Mayer and Baltimore 1994).

To gain insight into the regulation and function of the c-Abl tyrosine kinase we sought to identify proteins that interact directly and specifically with the regulatory $\mathrm{Abl}$ SH3 domain. Here we report the identification, cloning, and characterization of $\mathrm{Abi}-2$, an $\mathrm{Abl}$-interactor protein from human lymphocytes. Abi-2 is a member of a novel family of SH3-containing proteins that exhibit homology to homeo-domain proteins (Scott et al. 1989; Pabo and Sauer 1992). Two other genes homologous to abi-2 are the Xenopus laevis xlan 4 gene (Reddy et al. 1992) and mouse $a b i-1$ (Shi et al., this issue).

\section{Results}

Cloning of an $\mathrm{Abl}$ interacting protein by the yeast two-hybrid system

To identify proteins that interact with the Abl regulatory domains we employed the yeast two-hybrid system (Fields and Song 1989). A human lymphocyte library was screened, as genetic and biological data suggest that c-Abl plays a role in lymphocyte development (Caracciolo et al. 1989; Schwartzberg et al. 1991; Tybulewicz et al. 1991). Using the Abl SH3 domain as bait, we identified 24 positive clones out of $4 \times 10^{5}$ transformants. Among these, clone AS3B2 was demonstrated to confer a bait plasmid-dependent expression of $l a c Z$ in yeast strain Y190 and grew in his ${ }^{-}$, trp $^{-}$, leu $^{-}$selection plates with $25 \mathrm{~mm}$ 3-aminotriazole (3-AT) (data not shown). Nucleotide sequence analysis revealed that AS3B2 contains a single long open reading frame (ORF). The complete coding sequence of AS3B2 encompasses 1203 nucleotides. The gene contained in AS3B2 was designated $a b i-2$ for $\underline{\mathrm{Ab}} \mathrm{interactor} 2$. The corresponding protein product was referred to previously as Aip-1 (Abl interacting protein 1) (Feller et al. 1994b). The amino acid sequence of Abi- 2 is shown in Figure 1A.

\section{Abi-2 encodes an SH3-containing, proline-rich protein that exhibits homology to DNA-binding proteins}

Analysis of the predicted amino acid sequence of Abi-2 reveals several interesting features (Fig. 1A,B). The carboxy-terminal region of the protein encodes an $\mathrm{SH} 3$ domain (amino acids 346-397). Alignment of the Abi-2 SH3 domain with SH3 domains found in other proteins reveals the highest identity with the $\mathrm{SH} 3$ domains from cortactin $(53 \%)$, the hematopoietic specific protein HS1 $(48 \%)$, vav $(46 \%)$, phospholipase C- $\gamma(47 \%)$, and the Nck adaptor protein $(46 \%)$. Several proline-rich stretches are found in Abi-2 (Fig. 1A,B) that constitute potential binding sites for $\mathrm{SH} 3$ domain-containing proteins and contain the consensus PXXP sequence that is present in all high-affinity SH3 ligands identified to date (Rickles et al. 1994; Cohen et al. 1995). Also, a polyproline stretch is found upstream of the SH3 domain of Abi-2, which could function as a transcriptional activation domain (Tanaka et al. 1994). Sequences enriched in serine/threonine, glutamate/aspartate, and proline residues, designated PEST regions, are also found in Abi-2. Three PEST regions are identified in the central and carboxy-terminal portions of Abi-2 (Fig. 1A,B). PEST sequences have been implicated in increased susceptibility to protein degradation (Rogers et al. 1986). The amino-terminal region of Abi-2 is extremely basic with a calculated pI of 11.4 , whereas the carboxy-terminal portion is markedly acidic with a pI of 3.5. A serine-rich region is found in the central portion of Abi-2 (Fig. 1A,B). The protein contains nine serine/thre- 
A

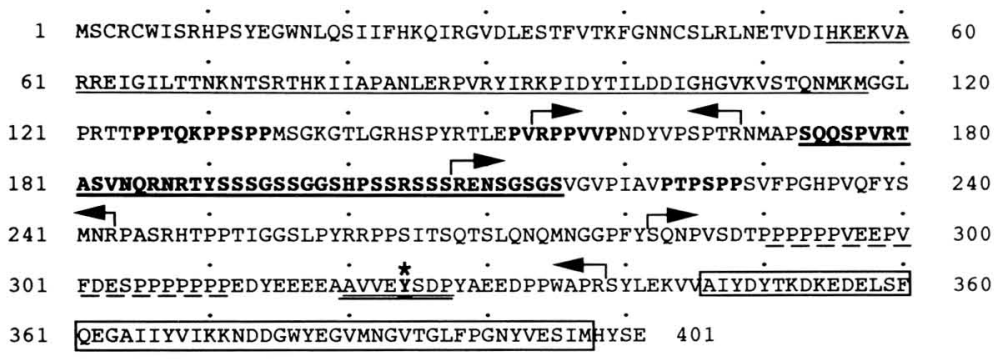

B

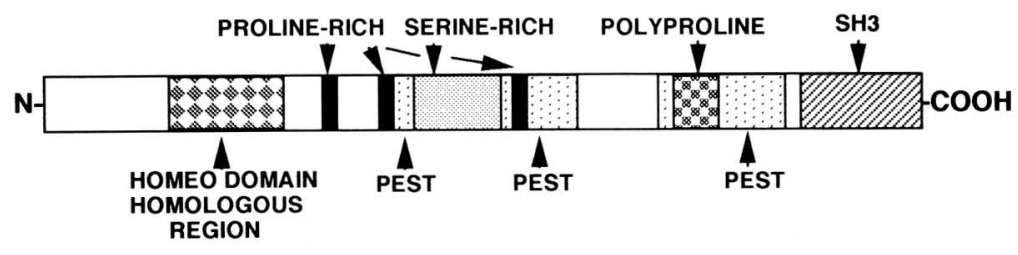

C
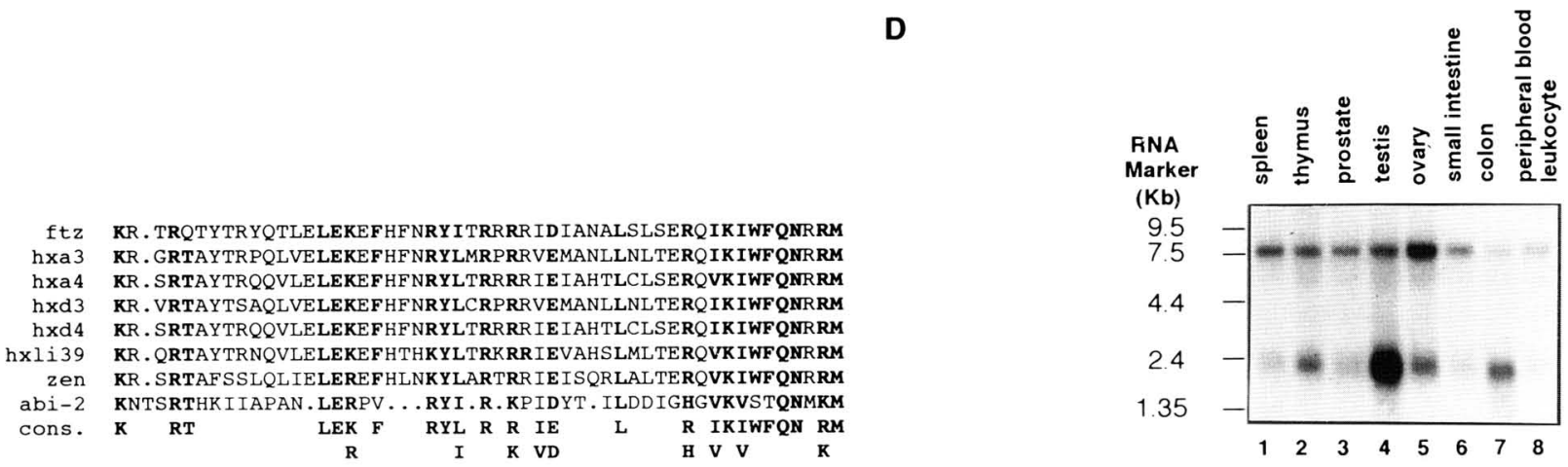

Figure 1. Sequence and Northern blot analysis of Abi-2. $(A)$ Predicted amino acid sequence of human Abi-2. Sequences in the carboxyl terminus corresponding to the SH3 domain are boxed. The three potential SH3-binding sites are in boldface type and a serine-rich region is bold and underlined. A potential c-Abl tyrosine phosphorylation site is doubly underlined, and the tyrosine is marked with an asterisk. Three PEST regions are bracketed with arrows and a homeo-domain homologous region at the amino terminus is underlined. A polyproline stretch is underlined with dashed lines. $(B)$ Diagram of structural features of Abi-2. $(C)$ Alignment of the Abi-2 homeo-domain homologous region with several homeo-domains. The consensus sequence is shown at the bottom. $(D)$ Northern blot analysis of $a b i-2$ expression in human tissues. Two micrograms of poly $(\mathrm{A})^{+}$RNA from the indicated human tissues was hybridized to ${ }^{32} \mathrm{P}$-labeled full-length $a b i-2$ cDNA probe. The RNA markers are indicated at left.

onine residues followed by proline, suggestive of potential phosphorylation by proline-directed protein kinases (Kemp and Pearson 1990). Three sites conform to the cdc2 kinase consensus sequence Ser/Thr-Pro- $X$-basic (Moreno and Nurse 1990). There are also 11 potential cAMP-dependent protein kinase sites and 9 potential protein kinase C sites (Kemp and Pearson 1990). Several tyrosines in the Abi-2 sequence are found in peptides that correspond to optimal peptide substrates for the $\mathrm{Abl}, \mathrm{Fps}$, and Src protein tyrosine kinases (Songyang et al. 1995).

Interestingly, the basic, amino-terminal region of Abi- 2 exhibits $40 \%-50 \%$ similarity over a 53 -aminoacid stretch to the DNA-binding region of homeo-domain proteins (Figure 1A-C) (Rushlow et al. 1987; Scott et al. 1989; Pabo and Sauer 1992). Homeo-domain proteins have been implicated in specifying positional information in the embryo during development and in the control of cell lineages by regulating the expression of cell type-specific genes (Scott et al. 1989). It is significant that all of the amino acids in the homeo domain that are implicated in contacting the DNA major groove are conserved in the basic region of Abi-2. Similarly, all of the amino acids that contact the DNA backbone, with the exception of an invariant tryptophan, are present in this domain of Abi-2 (Fig. 1C) (Pabo and Sauer 1992).

A search of the data base for homologous sequences revealed that the $a b i-2$ DNA sequence is $70 \%$ identical to that of the $X$. laevis xlan 4 DNA (Reddy et al. 1992). The predicted amino acid sequence of the Xlan 4 protein is $93 \%$ identical to that of the last 286 amino acids of Abi-2. Remarkable conservation of the SH3 domain, PEST sequences, serine-rich region, proline-rich stretches, and phosphorylation sites is observed among the human Abi-2 and predicted Xenopus Xlan 4 proteins. The xlan 4 gene is expressed as a maternal transcript and 
localizes in the animal pole region of the oocyte. The expression of xlan 4 is developmentally regulated (Reddy et al. 1992). More recently, a mouse gene with high homology to the human $a b i-2$ gene was cloned as a cDNA encoding an Abl-binding protein (Shi et al., this issue). The corresponding protein was designated Abi-1, Abl interactor 1 , and its predicted amino acid sequence is $65 \%$ identical to that of Abi-2.

\section{Abi-2 is widely expressed in human tissues}

To investigate the expression pattern of $a b i-2$, we performed Northern blot analysis on poly(A)-selected RNA from multiple human tissues. Using the $a b i-2$ cDNA as a probe, we detected two transcripts, 7 and $1.9 \mathrm{~kb}$, respectively, in all tissues examined (Fig. 1D). The abundance of the two transcripts varies among tissues (Fig. 1D). The expression of the 7-kb transcript appears constant in most tissues examined, with the exception of colon and peripheral blood leukocytes where low levels of the transcript are detected. Although detectable in almost all tissues examined, the $1.9-\mathrm{kb}$ transcript is relatively abundant in testes, ovary, thymus, and colon, with lower but detectable levels in prostate, peripheral blood leukocytes, and spleen. The entire $a b i-2$ cDNA obtained encompasses $\sim 1800$ nucleotides and contains in-frame termination codons in the $5^{\prime}$-untranslated region as well as consensus sequences for polyadenylation in the $3^{\prime}$ untranslated region. Thus, it is most likely that $a b i-2$ corresponds to the $1.9-\mathrm{kb}$ transcript. The $7-\mathrm{kb}$ transcript may be the product of a related gene or an alternative spliced form of the $a b i-2$ gene. Further experiments are needed to address these possibilities and identify other abi-2-related transcripts.

\section{$A b i-2$ binds to $c-A b l$ in vitro and in vivo}

We have shown that Abi-2 binds to the $\mathrm{Abl} \mathrm{SH} 3$ domain in yeast. To determine whether Abi-2 can interact with the full length c-Abl protein, a glutathione $S$-transferase (GST)-Abi-2 fusion protein was used in an in vitro binding assay with full-length c-Abl produced in baculovirusinfected insect cells (Pendergast et al. 1993). As shown in Figure 2A, the GST-Abi-2 protein interacts with fulllength $\mathrm{c}-\mathrm{Abl}$ in solution. The binding of $\mathrm{Abi}-2$ to $\mathrm{c}-\mathrm{Abl}$ appears to be selective, as shown by the failure of Abi-2 to form a complex with another SH3-containing protein, the guanosine triphosphatase-activating protein (GAP) of Ras (Fig. 2A, lanes 4-6; Trahey et al. 1988). To examine further the specificity of the interaction of the Abl SH3 domain with Abi-2, we compared a number of $\mathrm{SH} 3$ domains from distinct proteins for their ability to bind Abi2. We failed to detect interactions between $\mathrm{Abi}-2$ and the SH3 domains of Crk, Grb2, GAP, Src, and the p67 protein from neutrophils (data not shown). These results indicate that the interaction between $\mathrm{Abi}-2$ and the $\mathrm{Abl}$ SH3 domain is highly specific.

To examine the interaction of Abi-2 with c-Abl in vivo we developed antibodies to the Abi-2 protein. Interestingly, analysis of the Abi-2 protein by SDS-PAGE re-
A
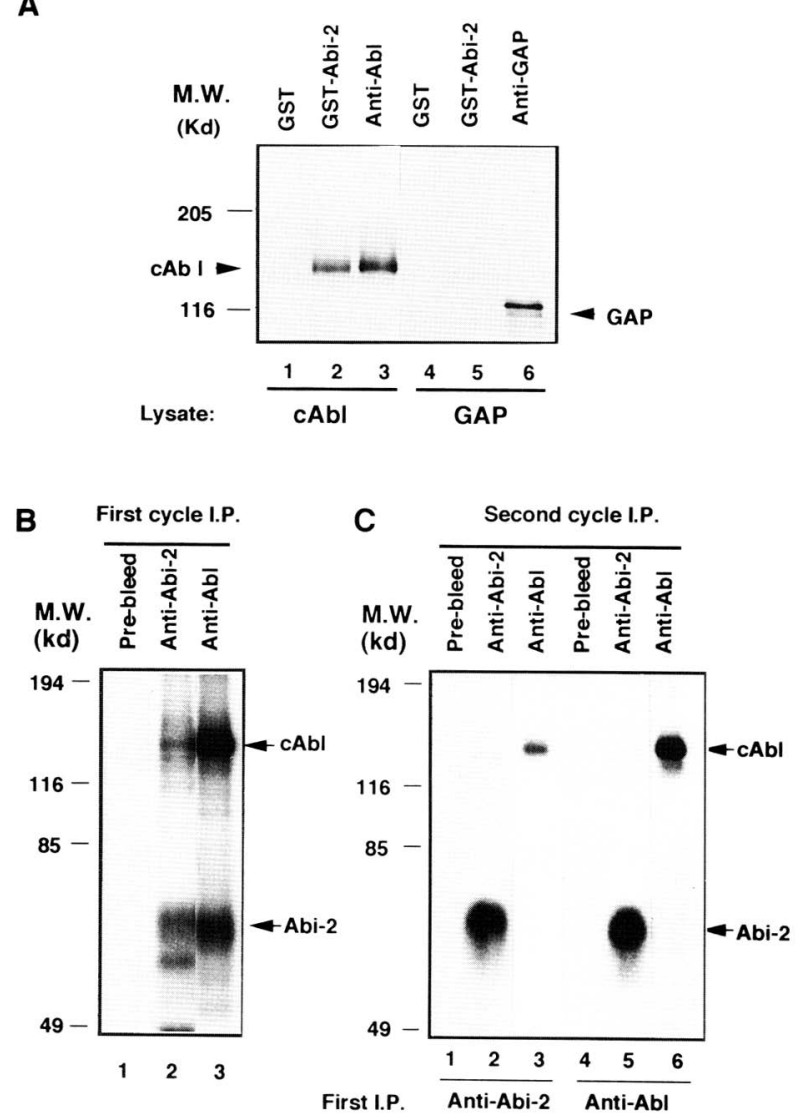

Figure 2. Abi-2 interacts with c-Abl. $(A)$ Sf9 insect cells were infected with either c-Abl or GAP recombinant baculoviruses and labeled with $\left[{ }^{35} \mathrm{~S}\right]$ methionine. Cell lysates were incubated with equal amounts of immobilized GST alone (lanes 1,4), GST-Abi-2 (lanes 2,5), and anti-Abl (lane 3) or anti-GAP (lane 6) antibodies bound to protein $\mathrm{A}-\mathrm{Sepharose}$ beads. After incubation for $90 \mathrm{~min}$ at $4^{\circ} \mathrm{C}$, the beads were washed with RIPA buffer to remove unbound material. Bound proteins were separated on SDS-PAGE and visualized by fluorography. The positions of $\mathrm{c}-\mathrm{Abl}$ and GAP are indicated. (B) Bosc 23 cells cotransfected with the $\mathrm{pSR} \alpha / \mathrm{c}-a b I$ and $\mathrm{pCGN} / a b i-2$ expression vectors were lysed and immunoprecipitated with preimmune serum (lane 1), anti-Abi-2 (lane 2), and Anti-Abl antibodies (lane 3). The immunoprecipitated proteins were subjected to an in vitro kinase assay in the presence of $\left[\gamma^{-32} \mathrm{P}\right] \mathrm{ATP}$. The phosphorylated proteins were separated on SDS-PAGE and visualized by autoradiography. (C) Following immunoprecipitation (I.P.) and kinase assay as described in $B$, the bound proteins were eluted from the immune complexes by boiling in the presence of SDS-PAGE sample buffer and subjected to a second cycle I.P. with the indicated sera.

vealed that Abi-2 migrates aberrantly. While the calculated molecular mass of the protein encoded by the $a b i-2$ cDNA is $44 \mathrm{kD}$, the Abi-2 protein produced in bacteria or translated in vitro in a reticulocyte lysate migrates with an apparent molecular mass of $55 \mathrm{kD}$ (Fig. 4B; data not shown). In addition to the major $55-\mathrm{kD}$ band, two proteins of $44-\mathrm{kD}$ and $75-\mathrm{kD}$ are obtained following in vitro transcription/translation using the $a b i-2$ cDNA, which 
are recognized by an anti-Abi-2 polyclonal antibody raised against full-length Abi-2 (data not shown). The smaller $44-\mathrm{kD}$ protein is likely to be produced by translation from an internal initiation codon because it cannot be recognized by antibodies specific to the Abi-2 amino terminus (data not shown). The $75-\mathrm{kD}$ protein may result from additional post-translational modifications. A $75-\mathrm{kD}$ protein is the predominant product obtained following transfection of the $a b i-2$ cDNA in Bosc 23 human embryonic kidney cells (Fig. 2B,C). The 75-kD protein is recognized by anti-Abi-2 antibodies. The 75$\mathrm{kD}$ protein and a minor $55-\mathrm{kD}$ protein are also detected with the anti-Abi-2 polyclonal antibodies in lysates from human B lymphoid cells (data not shown). Aberrant protein migration has been reported for several proteins that belong to an emerging family of SH3-containing proteins. These proteins are rich in acidic amino acids and proline residues and contain basic amino-termini with one or more repeats of a helix-turn-helix motif (Kitamura 1989; Wu et al. 1991; Fukamachi et al. 1994; Takemoto et al. 1995). Members of this protein family include cortactin, HS1/SPY75, and the recently cloned LckBP1. The LckBP1 cDNA encodes a protein with a predicted molecular mass of $54-\mathrm{kD}$, but analysis of the protein isolated from hematopoietic cells reveals that the apparent molecular mass of LckBP1 is $85 \mathrm{kD}$ (Takemoto et al. 1995). Poor binding of SDS to the acidic portions of these proteins, coupled with the presence of additional posttranslational phosphorylations, have been proposed to explain the aberrantly slow mobility of these proteins.

Interaction of $\mathrm{Abi}-2$ with $\mathrm{c}-\mathrm{Abl}$ in vivo was examined following overexpression of wild-type c-Abl and $\mathrm{Abi}-2$ in Bosc 23 cells and immunoprecipitation with antisera to Abi-2 or c-Abl. Bosc 23 cells were transfected with $\mathrm{pCGN} / a b i-2$ and $\mathrm{pSR} \alpha / \mathrm{c}-a b l$ mammalian expression plasmids. After $21 / 2$ days the cells were lysed and the lysates were incubated with anti-Abl, anti-Abi-2, or preimmune sera. The immunoprecipitates were then subjected to in vitro kinase assays with $\left[\gamma^{32} \mathrm{P}\right] \mathrm{ATP}$ to radiolabel the proteins. A $145-\mathrm{kD}$ protein was precipitated by the anti-Abi-2 antibody but not the corresponding preimmune sera (Fig. 2B, lanes 1,2). The $145-\mathrm{kD}$ protein comigrated with a protein of the same size, which was immunoprecipitated with anti-Abl antibodies from the same cells (Fig. 2B, lane 3). The identity of the $145-\mathrm{kD}$ protein as $\mathrm{C}-\mathrm{Abl}$ was confirmed by subjecting the precipitated proteins to a second round of immunoprecipitation with anti-Abl antibodies (Fig. 2C). Thus, the c-Abl wild-type protein is precipitated with antibodies to Abi-2 as detected by its in vitro autophosphorylation activity.

A radiolabeled protein of $\sim 75-\mathrm{kD}$ was detected in both anti-Abi-2 and anti-Abl immunoprecipitates from lysates of Bosc 23 cells cotransfected with the pCGN/ $a b i-2$ and $\mathrm{pSR} \alpha / \mathrm{c}-a b l$ expression plasmids (Fig. 2B, lanes 2,3 ). To examine whether this protein was Abi-2, a portion of the immunoprecipitates was boiled in the presence of SDS to denature the proteins and disrupt protein/ protein interactions, diluted with buffer lacking SDS, and then incubated with anti-Abi-2 antibodies or the corresponding preimmune sera. A $75-\mathrm{kD}$ protein was pre- cipitated with anti-Abi-2, but not the preimmune sera from both the anti-Abi-2 and anti-Abl immunoprecipitates of the Bosc 23 cell lysates (Figure 2C, lanes 1,2,4,5). These results show that full-length Abi-2 interacts with c-Abl following overexpression of both proteins in Bosc 23 cells and that Abi- 2 becomes phosphorylated in an in vitro kinase assay in the presence of the c-Abl tyrosine kinase. We have also observed that endogenous Abi-2 coimmunoprecipitates with the endogenous $\mathrm{C}-\mathrm{Abl}$ protein in B cell lysates (data not shown).

\section{Abi-2 binds to multiple surfaces on the $c$-Abl protein}

To confirm that the Abl SH3 domain was responsible for the interaction between $\mathrm{c}-\mathrm{Abl}$ and $\mathrm{Abi}-2$, we examined whether a mutant $\mathrm{c}-\mathrm{Abl}$ protein lacking the $\mathrm{SH} 3$ domain was deficient in binding to Abi-2. To our surprise, the c-Abl $\triangle \mathrm{SH} 3$ mutant bound to Abi-2 as efficiently as wildtype c-Abl (Fig. 3A). This result suggested that in addition to the $\mathrm{SH} 3$ domain, other sequences in c-Abl may participate in binding to Abi-2. Using both the yeast twohybrid system and in vitro binding assays, we identified a second region in the carboxyl terminus of $\mathrm{c}-\mathrm{Abl}$ that interacted strongly with Abi-2 (Fig. 3B). The Abi-2-binding region in the carboxyl terminus of $\mathrm{c}-\mathrm{Abl}$ maps to sequences near the NLS. Recently, it was reported that three distinct proline-rich sites in the Abl carboxyl terminus are binding sites for the $\mathrm{SH} 3$-containing Crk, Grb2, and Nck adaptor proteins (Ren et al. 1994). The presence of an SH3 domain in Abi-2 suggested that Abi-2 may also interact with $\mathrm{c}-\mathrm{Abl}$ by direct binding of the $\mathrm{Abi}-2 \mathrm{SH} 3$ domain with the proline-rich sequences in the carboxyl terminus of $\mathrm{c}-\mathrm{Abl}$.

To define more precisely the Abi-2 binding site in the $\mathrm{Abl}$ carboxyl terminus, additional c-Abl mutants were created and tested for binding to Abi-2 (Fig. 3C). Two of the three proline-rich stretches identified in c-Abl that bind to $\mathrm{SH} 3$ domains are found upstream of the nuclear localization sequence while the third proline stretch is downstream of this sequence (Ren et al. 1994). Deletion of the two proline-rich sites upstream of the NLS $(\Delta 544$ 601) did not diminish binding of c-Abl $\triangle \mathrm{SH} 3$ to Abi-2 (Fig. 3C, lane 8). In contrast, deletion of additional sequences, including the third proline-rich site $(\Delta 544-637)$, completely abolished binding of c-Abl $\triangle \mathrm{SH} 3$ to $\mathrm{Abi}-2$ (Fig. 3C, lane 11). These results indicate that Abi-2 binds to c-Abl by interacting directly with the $\mathrm{Abl} \mathrm{SH} 3$ domain and a proline-rich stretch downstream of the nuclear localization signal in the Abl carboxyl terminus.

\section{$c-A b l$ binds to the proline-rich amino terminus and carboxy-terminal SH3 domain of Abi-2}

To map the sites on Abi- 2 that interact with c-Abl, a series of Abi-2 deletion mutants was generated (Fig. 4A) and tested for binding to GST-fusion proteins containing the $\mathrm{Abl} \mathrm{SH3}$ domain and $\mathrm{Abl}$ carboxy-terminal sequences (Fig. 4B,C). Full-length and carboxy-terminal truncated $\mathrm{Abi}-2$ proteins were synthesized by in vitro 
A

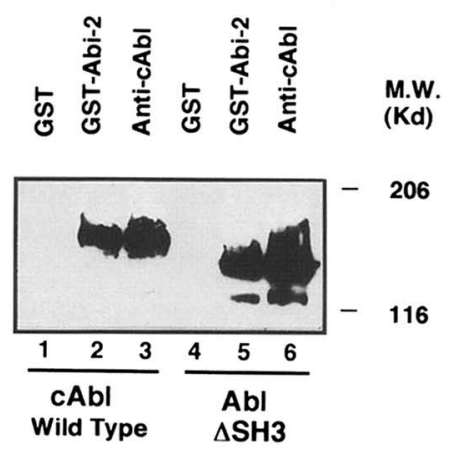

B

aa

\begin{tabular}{l}
$100 \quad 20030040050060070080090010001100$ \\
\hline
\end{tabular}

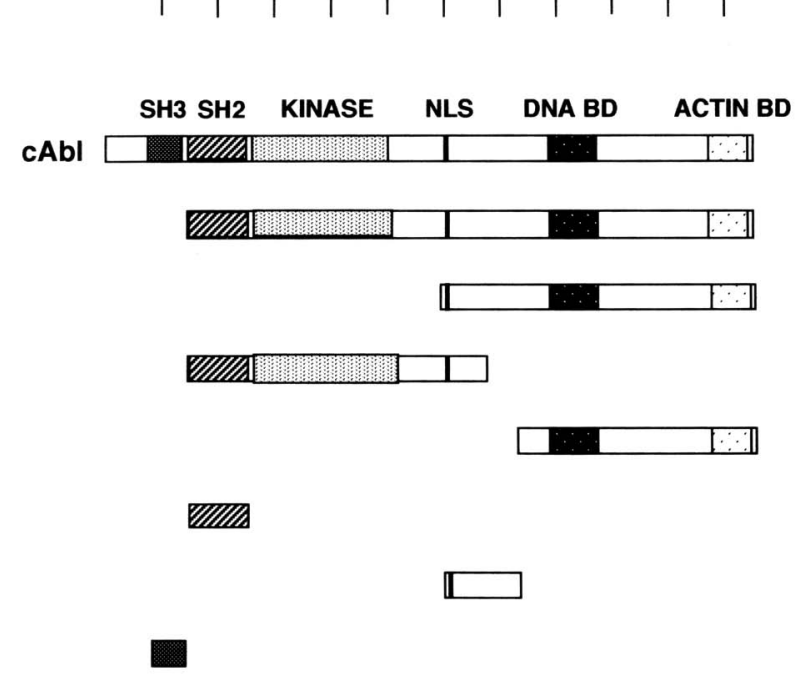

C

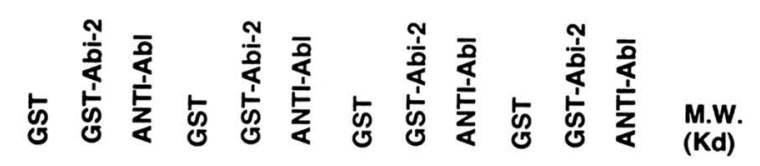

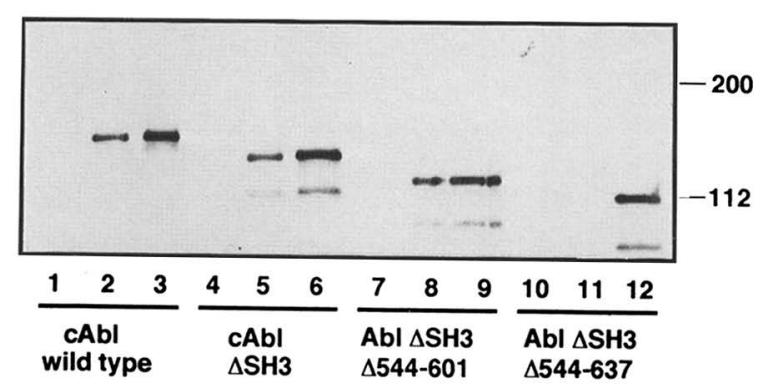

Figure 3. Abi-2 binds to c-Abl at both $\mathrm{SH} 3$ and carboxy-terminal regions. $(A)$ Interaction of $\mathrm{Abi}-2$ with c-Abl is retained following deINTERACTION WITH Abi-2 letion of the c-Abl SH3 domain. Lysates of COS cells transfected with expression vectors encoding wild-type c-Abl (pSR $\alpha / c-a b l)$ (Lanes 1-3) or an $\mathrm{SH} 3$ deletion mutant of c-Abl (pSR $\alpha / \mathrm{c}-a b l \Delta \mathrm{SH} 3$ ) (lanes 4-6) were incubated with immobilized GST alone (lanes 1,4), GST-Abi-2 (lanes 2,5), or anti-Abl antibodies bound to protein A-Sepharose beads (lanes $3,6)$. Bound proteins were separated on SDSPAGE, transferred to nitrocellulose, and immunoblotted with anti-Abl antibodies. (B) Mapping of the Abi-2-binding sites on c-Abl. Wild-type c-Abl and c-Abl deletion mutants are shown schematically. Binding of c-Abl fragments to Abi-2 was determined by the yeast two-hybrid system assay or by an in vitro binding assay, as indicated at right. (NLS) Nuclear localization sequence; (BD) binding domain. $(C)$ Deletion of the Abl SH3 domain and $\mathrm{Abl}$ carboxy-terminal prolinerich sequences abolishes Abl binding to Abi-

2. The indicated in vitro-translated proteins were labeled with $\left[{ }^{35} \mathrm{~S}\right]$ methionine and incubated with GST alone, GST Abi-2, and anti$\mathrm{Abl}$ antibodies bound to protein A-Sepharose beads, as indicated. Bound proteins were analyzed by SDS-PAGE and the $\left[{ }^{35} \mathrm{~S}\right]$-labeled proteins were visualized by fluorography.

transcription/translation in a rabbit reticulocyte lysate. The predominant in vitro transcription/translation products generated from the full-length $a b i-2$ cDNA, migrate with apparent molecular masses of 55 and $44 \mathrm{kD}$ (Fig. 4B). Deletion of the Abi-2 SH3 domain abrogates binding to the proline-rich $\mathrm{Abl}$ carboxy-terminal sequences encompassing amino acids 593-730 (Fig. 4B, lane 6). Further deletion of sequences upstream of the Abi-2 SH3 domain, which contain a polyproline stretch and a PEST domain does not affect binding to the $\mathrm{Abl} \mathrm{SH3}$ domain (Fig. 4B, lane 8).

To identify the sequences in Abi-2 that mediate binding to the Abl SH3 domain, we generated additional Abi- 2 mutant proteins containing deletions of prolinerich sequences localized in the amino-terminal or central regions of the protein (Fig. 4A,C). The Abi-2 proteins were produced in mammalian COS cells and tested for binding to Abl sequences. As shown in Figure 4C, deletion of the most amino-terminal proline-rich stretch of Abi-2 eliminates binding to the Abl SH3 domain (Fig. $4 \mathrm{C}$, lane 5). Mutation of the individual prolines in this sequence is required to directly demonstrate that the interaction of the Abl SH3 domain with the amino-terminal sequences of Abi-2 is dependent on the presence of these proline residues. However, a 10-amino-acid proline-rich stretch within this region of Abi-2 exhibits strong similarity to the Abl SH3-binding site in 3BP-1 (Cohen et al. 1995), suggesting that this proline-rich sequence in Abi-2 is likely to bind to the Abl SH3 domain. Thus, our results indicate that the c-Abl tyrosine kinase contacts Abi-2 at a minimum of two sites: an aminoterminal proline-rich stretch and the $\mathrm{Abi}-2 \mathrm{SH} 3$ domain. 
A

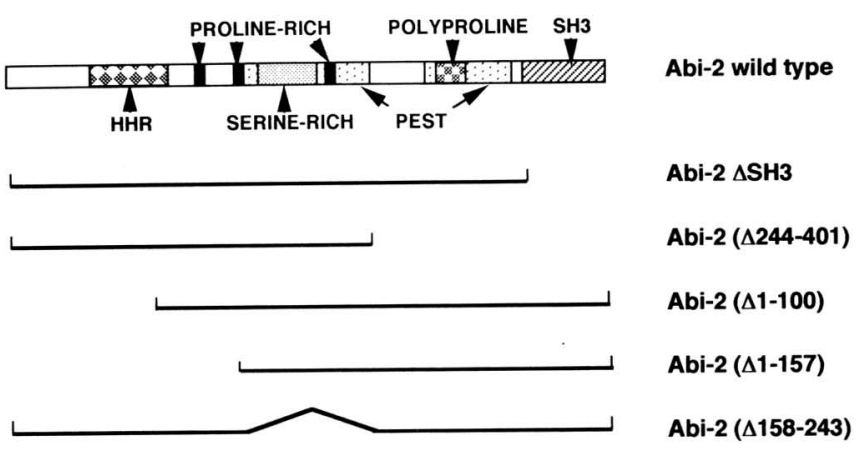

B

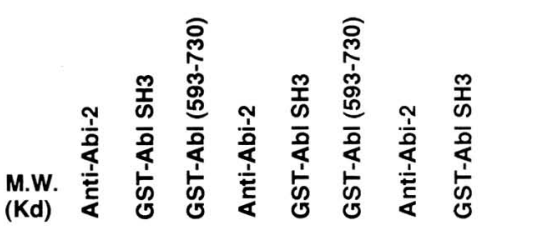

C
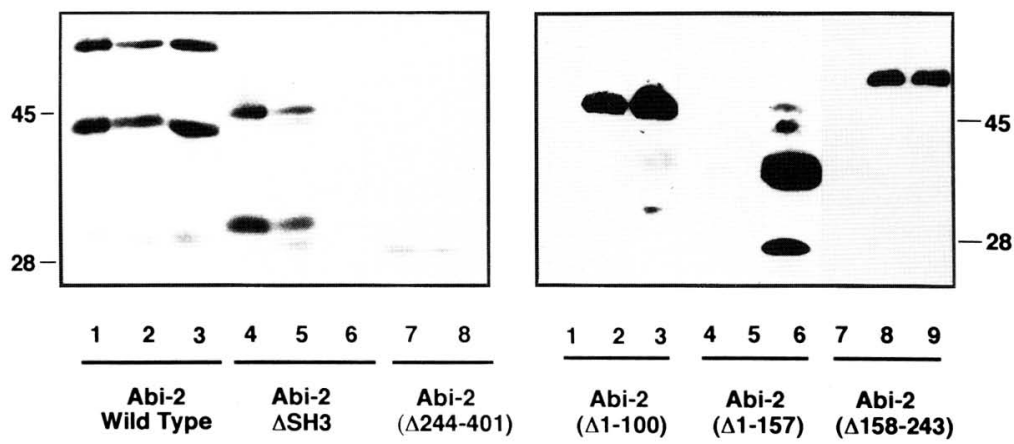

Figure 4. c-Abl binds to the proline-rich amino terminus and the carboxy-terminal SH3 domain of Abi-2. (A) Schematic representation of $\mathrm{Abi}-2$ and the Abi-2 deletion mutants constructed. The positions and names of the various structural domains in Abi- 2 are indicated. (HHR) Homeo-domain homologous region. (B) cDNAs encoding $a b i-2, a b i-2 \Delta S H 3$, and $a b i-2 \Delta 244-401$ were subcloned into the pGEM vector for in vitro transcription/translation. The ${ }^{35} \mathrm{~S}$-labeled translated proteins were incubated with anti-Abi- 2 antibodies bound to protein A (lanes 1,4,7), GST-Abl SH3 (lanes 2,5,8), and GST-Abl (593-730) (lanes 3,6). Bound proteins were washed and separated on SDS-PAGE, and ${ }^{35} \mathrm{~S}$-labeled proteins were visualized by fluorography. $(C)$ cDNAs encoding aminoterminal deletion mutants $(a b i-2 \Delta 1-100$ and $a b i-2 \Delta 1-157)$ or an internal deletion (abi-2 $\Delta 158$ 243) of Abi-2 were subcloned in-frame into the pCGN vector and transfected into COS cells. Cell lysates were prepared at $21 / 2$ days post-transfection, and the lysates incubated with GST alone (lanes 1,4,7), GST-Abl SH3 (lanes 2,5,8), and GST-Abl (593-730) (lanes 3,6,9). Bound proteins were separated on SDS-PAGE and analyzed by Western blotting with the anti-HA monoclonal antibody.
A model for the interaction between $\mathrm{c}-\mathrm{Abl}$ and $\mathrm{Abi}-2$ is shown in Figure 6D (below).

\section{Abi-2 is a substrate for the c-Abl tyrosine kinase in vitro and in vivo}

The strong association between $\mathrm{Abi}-2$ and $\mathrm{c}-\mathrm{Abl}$ suggested that Abi-2 may be a target for the tyrosine kinase activity of c-Abl. Additional support for this suggestion was provided by the observation that Abi- 2 became phosphorylated in immune complex in vitro kinase assays following coprecipitation with the c-Abl tyrosine kinase from Bosc 23 cell lysates coexpressing the two proteins (Fig. 2B,C). Phosphoamino acid analysis of Abi-2 demonstrated that the phosphorylation was exclusively on tyrosine residues (data not shown). To determine whether the purified Abi- 2 protein is a c-Abl substrate, wild-type and kinase defective forms of $\mathrm{c}-\mathrm{Abl}$ were synthesized by in vitro transcription/translation in a reticulocyte lysate (Fig. 5A) and tested for their ability to phosphorylate purified GST or GST-Abi-2 proteins in vitro. Abi-2 was phosphorylated by wild-type but not kinase-defective c-Abl (Fig. 5A). A c-Abl mutant protein, c-Abl $\Delta S H 3$ $\Delta 544-637$, which retains tyrosine kinase activity (data not shown) but is defective in binding to Abi-2 (Fig. 3C), did not phosphorylate Abi-2 in this assay (Fig. 5A, lane 6). Next, we examined whether Abi-2 could be phosphorylated in vivo by c-Abl following expression in Bosc 23 cells. Coexpression of Abi-2 with wild-type c-Abl resulted in a marked increase in Abi-2 tyrosine phosphorylation (Fig. 5B, lane 4). These data show that Abi-2 can be phosphorylated by the activated c-Abl tyrosine kinase in vivo.

\section{Expression of an Abi-2 mutant protein uncovers the transforming activity of $c-A b l$}

The findings that Abi-2 binds to c-Abl via dual SH3 domain/proline-rich sequence interactions and that $\mathrm{Abi}-2$ is a substrate of the c-Abl tyrosine kinase strongly suggested that Abi-2 may modulate the biological properties of c-Abl in the cell. Two biological assays are available to examine the effects of Abl expression in vivo. First, overexpression of c-Abl wild type in NIH-3T3 cells has been shown to elicit growth arrest and result in counterselection of the expression of the c-Abl protein (Jackson et al. 1993; Sawyers et al. 1994). Second, specific alterations in the c-Abl structure have been shown to result in cell transformation (Wang 1993). To examine whether Abi-2 can affect the biological properties of c-Abl, we trans- 
A

In Vitro Phosphorylation

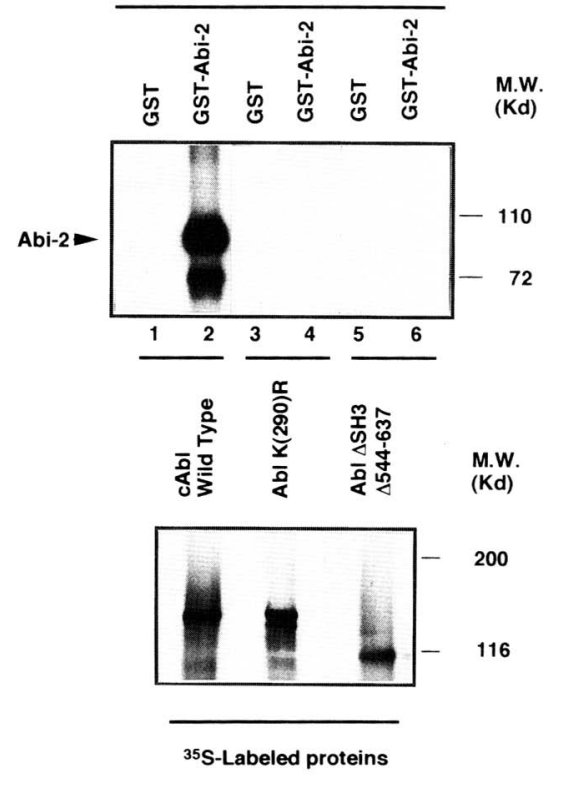

B

In Vivo Phosphorylation

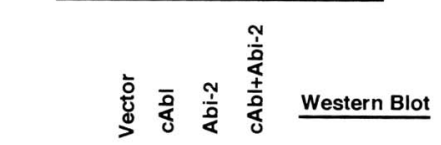

Figure 5. Abi-2 is phosphorylated in vitro and in vivo by c-Abl. $(A)$ In vitro phosphorylation. Immobilized GST alone (lanes $1,3,5$ ) or GST-Abi-2 (lanes $2,4,6$ ) were incubated at $4^{\circ} \mathrm{C}$ for $60 \mathrm{~min}$ with in vitro transcription/translation products (bottom) of c-Abl wild type (lanes 1,2), c-Abl K290R (lanes 3,4) and c-Abl $\Delta \mathrm{SH} 3 \quad \Delta 544-637$ (lanes 5,6). Bound proteins were subjected to in vitro phosphorylation at $30^{\circ} \mathrm{C}$ in the presence of $\left[\gamma^{-32} \mathrm{P}\right]$ ATP and $\mathrm{MnCl}_{2}$. The phosphorylated proteins bound to beads were washed three times, separated on SDS-PAGE, and visualized by autoradiography. $(B)$ In vivo phosphorylation. Bosc 23 cells were transfected with pCGN vector alone (lane 1), pSR $\alpha / \mathrm{c}-a b l$ (lane 2), pCGN/abi-2 (lane 3), and pSR $\alpha / \mathrm{c}-a b l$ plus pCGN/abi-2 (lane 4). Cell lysates were separated on SDS-PAGE and immunoblotted with the indicated antibodies. fected NIH-3T3 cells with hygromycin-containing mammalian expression vectors encoding full-length or truncated forms of Abi-2. Expression of full-length Abi-2 could not be detected following transfection and hygromycin drug selection. Like the Abl proteins, full-length Abi- 2 appears to exert cytotoxic and, possibly, cytostatic, effects on cells following overexpression (Ziegler et al. 1981; Renshaw et al. 1992; Jackson et al. 1993; Sawyers et al. 1994). In contrast, an amino-terminal truncated form of Abi-2 lacking the homeo-domain homologous region and the proline-rich sequences required for interaction with the $\mathrm{Abl} \mathrm{SH3}$ domain (Abi-2 $\Delta 1-157$ ) was readily expressed in NIH-3T3 cells (Fig. 6A). Cells stably expressing the Abi-2 $\Delta \mathrm{l}-157$ mutant or vector alone were infected with retroviruses encoding for wild-type c-Abl, a kinase-defective form of c-Abl, c-Abl K290R, or vector alone (Fig. 6B). A fraction of the cells was collected at $21 / 2$ days postinfection, lysed, and subjected to Western blot analysis with anti-Abl antibodies. Similar levels of c-Abl wild-type and c-Abl K290R proteins were detected in control NIH-3T3 cells and in NIH-3T3 cells that stably expressed the Abi-2 $\Delta 1-157$ mutant (Fig. 6B, top). At $21 / 2$ days postinfection the cells were selected with G418. Surprisingly, analysis of drug-selected cells at 22 days postinfection revealed that while the $\mathrm{c}-\mathrm{Abl}$ wild-type protein was counter-selected in control NIH$3 \mathrm{~T} 3$ cells in accordance with previous observations (Sawyers et al. 1994), c-Abl was expressed to high levels in NIH-3T3 cells that coexpressed the Abi-2 $\Delta 1-157 \mathrm{mu}-$ tant protein (Fig. 6B, lanes 2 and 5, bottom left). As shown previously, the kinase-defective c-Abl K290R protein was not counter-selected (Fig. 6B, lanes 3 and 6, bottom left). Furthermore, antiphosphotyrosine Western blot analysis revealed that expression of Abi-2 $\Delta 1-157$ activates the tyrosine kinase activity of $\mathrm{c}-\mathrm{Abl}$ in NIH-
3T3 cells (Fig. 6B, right). No enhanced tyrosine phosphorylation is detected in cells coexpressing Abi-2 $\Delta \mathrm{l}-157$ and a kinase-defective form of c-Abl (Fig. 6B, right).

A striking difference was observed among the cells coexpressing c-Abl wild-type and Abi-2 $\Delta 1-157$ and those cells expressing Abi-2 $\Delta 1-157$ alone, c-Abl alone, vector control, or coexpressing Abi-2 $\Delta 1-157$ and a kinase-defective form of c-Abl (Fig. 6C). Cells that coexpressed Abi-2 $\Delta \mathrm{l}-157$ and c-Abl wild type were morphologically transformed and exhibited a similar morphology to those $\mathrm{NIH}-3 \mathrm{~T} 3$ cells expressing the v-Abl oncoprotein (Fig. 6C, 3 and 6). To directly examine whether the cells coexpressing Abi-2 $\Delta 1-157$ and c-Abl wild type were transformed, we assayed for colony formation in soft agar as a measurement of anchorage-independent growth (Muller et al. 1991). As shown in Table 1 , cells coexpressing the Abi-2 $\Delta 1-157$ mutant and c-Abl wild type exhibit a dramatic increase in soft agar plating efficiency compared with cells expressing either protein alone or cells expressing both the Abi-2 $\Delta 1-157$ mutant and a kinasedefective form of $\mathrm{c}-\mathrm{Abl}$. These results demonstrate that expression of the Abi-2 $\Delta 1-157$ mutant protein activates the tyrosine kinase and transforming activities of $\mathrm{c}-\mathrm{Abl}$ in NIH-3T3 cells.

\section{Discussion}

Using a protein interaction cloning technique, we have identified a cDNA encoding a novel c-Abl-binding protein: Abi-2. Abi-2 interacts with at least two domains in $\mathrm{c}-\mathrm{Abl}$ and is a substrate for its tyrosine kinase activity. We have shown that c-Abl can be converted into a transforming protein by coexpression with an amino-terminal truncated form of Abi-2 in the absence of structural alterations on the c-Abl molecule itself. 
A

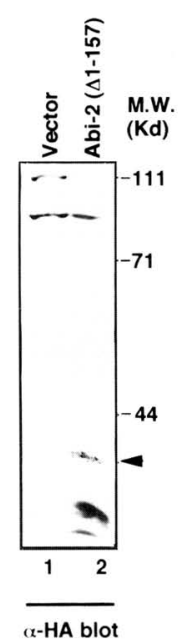

B

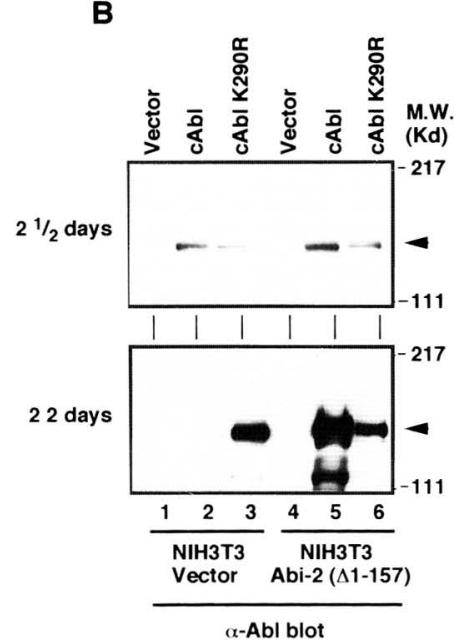

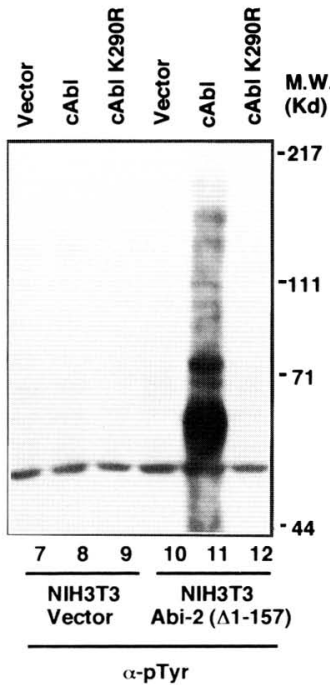

C
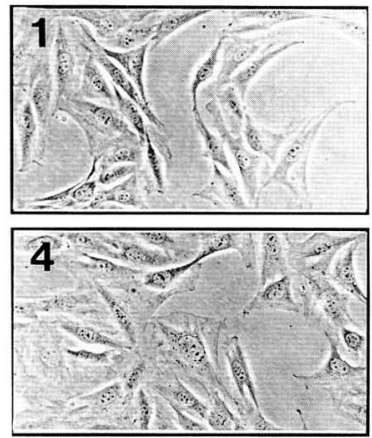

D

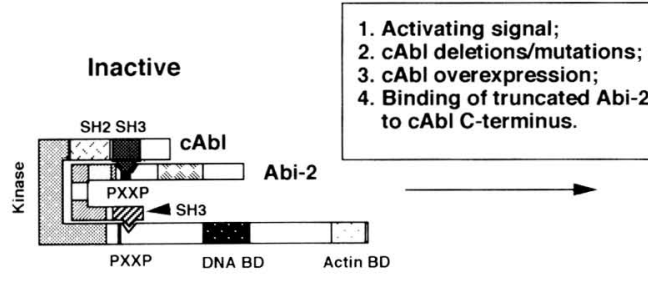

(Fig. 1D) and murine Abi-1 (Shi et al., this issue) suggests that the two proteins may belong to a protein family. Moreover, whereas the expression pattern of murine Abi-1 shows markedly higher levels in the brain, the human Abi-2 is ubiquitously expressed. An additional distinction between the two proteins is the absence in Abi- 2 of a second region of homology in murine Abi-1, which is found in a group of homeo-domain proteins /Shi et al., this issue). This region of homology lies outside the DNA-binding region and corresponds to a prolinerich segment of the protein. Our results indicate that the human $a b i-2$ gene localizes to a chromosome different
Figure 6. Expression of an Abi-2 mutant deficient in binding to the $\mathrm{Abl} \mathrm{SH} 3$ domain activates the tyrosine kinase and transforming properties of c-Abl. (A) Expression of Abi-2 $\Delta 1-157$ in NIH-3T3 cells. Cells were transfected with pCGN alone (lane 1) or pCGN/abi-2 $\Delta 1-157$ (lane 2). Following hygromycin selection, cells were lysed in sample buffer and subjected to Western blot analysis using anti-HA antibody. The Abi-2 $\Delta 1-157$ protein is indicated with the arrowhead. $(B)$ Abi-2 $\Delta 1-$ 157 reverses biologic selection against c-Abl overexpression. NIH-3T3 cells expressing Abi-2 $\Delta 1-157$ or vector control were infected with retroviruses encoding the neo resistance gene alone, c-abl wildtype or c-abl K290R, as indicated. After 2 $1 / 2$ days, cells were selected with G418. (Left) Anti-Abl Western blots of lysates prepared from infected cells at $21 / 2$ days (top) or 22 days postinfection (bottom). $\mathrm{c}-\mathrm{Abl}$ is indicated by the arrowhead. (Right) An anti-pTyr Western blot of lysates from cells at 22 days postinfection. (C) Abi-2 $\Delta 1-157$ activates the c-Abltransforming activity. NIH-3T3 cells were transfected with either pCGN vector (panels 1-3) or pCGN/abi-2 $\Delta 1-157$ (panels 4-6). After selection with hygromycin, the cells were infected with retroviruses expressing neo (1 and 4), wild type c-Abl (2 and 6), c-Abl K290R (5), or v-Abl (3). At 2 $1 / 2$ days postinfection the cells were incubated with media containing G418 and maintained under drug selection for 22 days. Morphological transformation was clearly observed in c-Abl-infected $\mathrm{NIH}$ 3T3 cells that had been transfected with Abi-2 $\Delta 1-157$ but not in cells expressing vector control (cf. 2 and 6). (D) A model is proposed for the interaction of $\mathrm{c}-\mathrm{Abl}$ and Abi-2 and the presence of c-Abl/Abi-2 complexes in unphosphorylated and tyrosine-phosphorylated states. Activation of the c-Abl tyrosine kinase leading to tyrosine phosphorylation of Abi-2 may occur by a variety of events, some of which are listed in the box.

e abi-1 gene (Z. Dai, T. Yang-Feng, and A.M. Pendergast, unpubl.).

A body of experimental data suggest that the tyrosine kinase and transforming activity of c-Abl is tightly regulated in vivo by a trans-acting protein inhibitor (Pendergast et al. 1991a; Mayer and Baltimore 1994). Several proteins have been identified that bind to specific domains in Abl and may be candidates for the c-Abl inhibitor. Two proteins, 3BP-1 and 3BP-2, have been identified by screening of a $\lambda \mathrm{gt} 11 \mathrm{cDNA}$ expression library with the Abl SH3 domain (Cicchetti et al. 1992). However, neither protein has been shown to interact with fulllength c-Abl in vivo (Mayer and Baltimore 1994). An in- 
Table 1. Transformation of NIH-3T3 cells by coexpression of $c-A b l$ and a truncated $A b i-2$ protein

\begin{tabular}{lcc}
\hline & \multicolumn{2}{c}{ No. of agar colonies $^{\mathrm{b}}$} \\
\cline { 2 - 3 } Retroviruses $^{\mathrm{a}}$ & NIH-3T3 vector $^{\mathrm{c}}$ & NIH 3T3/Abi-2 $\Delta 1-157^{\mathrm{c}}$ \\
\hline c-Abl wild type & 3 & 563 \\
c-Abl K290R & 2 & 3 \\
Tkneo & 4 & 3
\end{tabular}

${ }^{a}$ Helper-free retroviruses were prepared by transient overexpression in Bosc 23 cells as described in Materials and methods. ${ }^{b}$ Number of agar colonies per $10^{4}$ cells. The average frequency of colony formation in soft agar was determined from two plates per assay. Colonies with a diameter of $>0.5 \mathrm{~mm}$ were counted $\sim 2$ weeks after plating the cells.

${ }^{\mathrm{c}} \mathrm{NIH}-3 \mathrm{~T} 3$ cells stably transfected with either pCGN vector alone or pCGN/abi-2 $\Delta 1-157$ were infected with the indicated helper-free retroviruses. At $21 / 2$ days postinfection the cells were selected with G148 and cultured for 3 weeks in the presence of the drug.

teraction of c-Abl with the retinoblastoma protein $(\mathrm{Rb})$ has been reported (Welch and Wang 1993). Rb interacts with $\mathrm{Abl}$ by binding to the Abl tyrosine kinase domain and inhibits its kinase activity (Welch and Wang 1993). The observation that only $5 \%-25 \%$ of the total $\mathrm{c}-\mathrm{Abl}$ is present in a complex with $\mathrm{Rb}$ while all of the $\mathrm{c}-\mathrm{Abl}$ in the cell is inhibited suggests that additional mechanisms regulate the $\mathrm{c}-\mathrm{Abl}$ tyrosine kinase, possibly through interactions with other cellular proteins. More recently, it was shown that $\mathrm{c}-\mathrm{Abl}$ interacts with the Crk family of SH3-containing adaptor proteins (Feller et al. 1994a; Ren et al. 1994). The cytosolic Crk proteins bind to the c-Abl carboxy-terminal domain (Ren et al. 1994). No inhibitory effect of Crk binding on the c-Abl tyrosine kinase was reported. The results presented here show that Abi-2 forms a complex with c-Abl through direct contact with both the Abl SH3 and carboxy-terminal domains and modulates c-Abl activity. The proposed regulatory function of Abi-2 may involve stabilization of the inactive form of c-Abl or, alternatively, Abi- 2 may block access to critical cellular protein substrates of the c-Abl tyrosine kinase. The latter hypothesis is consistent with the inhibitory effect of the related murine Abi-1 protein on the transforming activity of the $\mathrm{P} 160^{\mathrm{v}-a b l}$ tyrosine kinase (Shi et al., this issue).

A second role for Abi-2 that is suggested from the data presented here is that of effector of the c-Abl protein tyrosine kinase. Abi-2 is a substrate for $\mathrm{c}-\mathrm{Abl}$ in vitro and in vivo. At least two tyrosines within Abi-2 are found in sequences predicted to be optimal peptide substrates for the c-Abl tyrosine kinase (Songyang et al. 1995). The optimal phosphorylation site corresponds to the tyrosine in the sequence YSDP just upstream of the Abi-2 SH3 domain (Fig. 1A). A tyrosine in a similar context was reported to be the site phosphorylated by c-Abl on c-Crk (Feller et al. 1994a). These results support a role for the $\mathrm{Abl} \mathrm{SH} 3$ and carboxy-terminal domains in substrate recruitment. Recruitment of c-Abl substrates through di- rect protein interactions is also illustrated by the binding of Enabled to the Drosophila Abl protein, which is mediated by direct interaction of the proline-rich sequences in Enabled with the Abl SH3 domain (Gertler et al. 1995). The Enabled protein is phosphorylated by the Abl tyrosine kinase, and this phosphorylation is proposed to regulate Enabled function during axogenesis (Gertler et al. 1995).

In addition to the dual SH3-proline interactions within the c-Abl/Abi-2 complex, contacts may be made between tyrosine-phosphorylated sequences in Abi-2 and the Ab1 SH2 domain. It has been shown that protein tyrosine kinases preferentially phosphorylate peptide sequences that bind with high affinity to their own SH2 domains (Songyang et al. 1995). This type of interaction may protect Abi-2 from dephosphorylation and strengthen the interaction between Abi- 2 and c-Abl. In this regard, a role for the $\mathrm{Abl} \mathrm{SH} 2$ domain in substrate selectivity has been described recently. The Abl SH2 domain is required for the efficient in vitro hyperphosphorylation of multiple tyrosines present in the carboxyterminal domain of RNA polymerase II and p130 CAS (Duyster et al. 1995; Mayer et al. 1995).

The most revealing result presented here is the finding that overexpression of a truncated form of $\mathrm{Abi}-2$, which has lost the sequences required for binding to the $\mathrm{Abl}$ $\mathrm{SH} 3$ domain but retains binding to the Abl carboxyl terminus, converts c-Abl into a transforming protein. Several models may be proposed to explain this result. The Abi-2 $\Delta 1-157$ protein may simply displace the endogenous Abi-2 protein and thereby allow constitutive phosphorylation of other protein targets by the c-Abl tyrosine kinase. Alternatively, binding of Abi-2 $\Delta 1-157$ to the Abl carboxyl terminus may activate its tyrosine kinase activity and transforming potential. These two possibilities may not be mutually exclusive. An additional mechanism whereby Abi- $\Delta 1-157$ could elicit transformation is by retaining $\mathrm{c}-\mathrm{Abl}$ in the cytoplasm and thereby keeping c-Abl outside of the nucleus. It has been proposed that the growth inhibitory activity of overexpressed $\mathrm{c}-\mathrm{Abl}$ requires localization to the nuclear compartment (Sawyers et al. 1994).

What is the cellular role of Abi-2 and related family members? The Abi proteins may function to coordinate the cytoplasmic and nuclear functions of the c-Abl tyrosine kinase. Subcellular fractionation reveals that Abi-2, like c-Abl, is found in both the cytoplasm and the nucleus (data not shown). Abi-2 contains protein motifs associated with cytoplasmic signaling proteins ( $\mathrm{SH} 3$ domain) as well as with nuclear factors (homeo-domain homology domain, PEST sequences, and polyproline and acidic domains similar to those present in the activation domains of transcription factors). An attractive possibility is that Abi-2 may function in a manner analogous to that of the signal transducers and activators of transcription (STATs), which become tyrosine phosphorylated in response to extracellular stimuli and migrate into the nucleus where they bind to DNA and activate transcription (Darnell et al. 1994).

Abi-2 may represent a class of signaling molecules that 
have evolved to specifically couple signals elicited by activated protein tyrosine kinases to specific changes in the nucleus, the cytoskeleton, and other cellular compartments. Although Abi-2 does not share significant sequence identity with other known proteins, it exhibits a very similar structural arrangement to that of proteins implicated in signaling by the Src family of tyrosine kinases: HS1 (Yamanishi et al. 1993) and cortactin (Wu et al. 1991|. Both proteins are only $20 \%$ identical to Abi-2; however, all three have an SH3 domain at the carboxyl terminus, contain proline-rich sequences, a basic amino terminus with helix-turn-helix motifs and, significantly, all three proteins have a potential site of tyrosine phosphorylation just upstream of the $\mathrm{SH} 3$ domain. HS1 is expressed exclusively in hematopoietic cells and has been shown to be a major substrate of the Lyn tyrosine kinase upon B cell stimulation (Yamanashi et al. 1993). Like Abi-2, HS1 has been shown to localize to the cytoplasm and the nucleus (Yamanishi et al. 1993). Cortactin is a substrate of the Src tyrosine kinase and associates with the cytoskeleton (Wu et al. 1991). More recently, another member of this family, LckBPl, was cloned as a protein that interacts with the LckSH3 domain (Takemoto et al 1995). These proteins may play critical roles in the transmission of growth, differentiation, stress, and apoptotic signals elicited by specific protein tyrosine kinases. Further work is necessary to determine whether Abi-2, HS1, LckBP1, and cortactin share similar functional roles.

The identification of $\mathrm{Abi}-2$ as a substrate of the $\mathrm{c}-\mathrm{Abl}$ tyrosine kinase, which like c-Abl is found in the cytoplasm and the nucleus, and the finding that alterations in Abi-2 can activate the c-Abl-transforming potential provide new directions in the investigation of $\mathrm{c}-\mathrm{Abl}$ functions. A role for Abi- 2 in cancer may be hypothesized. Mutations or deletions in Abi-2 could be associated with the progression of Philadelphia chromosomepositive human leukemias from the chronic to the blast crisis phases of the disease. Alterations in Abi-2 could also potentially be linked to the development of other cancers.

\section{Materials and methods}

\section{Cells and viruses}

Recombinant c-Abl baculovirus was prepared as described (Pendergast et al. 1991b). Recombinant GAP baculovirus (Trahey et al.1988) was obtained from Drs. R. Clark and F. McCormick. Bosc 23 cells, obtained from Drs. W.S. Pear and D. Baltimore (Pear et al. 1993), were grown in Dulbecco's modified Eagle medium (DMEM) with $10 \%$ fetal calf serum (FCS); COS and NIH-3T3 cells were grown in DMEM plus 5\% FCS; Sf 9 insect cells were grown in Grace media plus yeastolate and 10\% FCS.

\section{Antibodies}

Polyclonal antibodies against Abi-2 were prepared by immunization of New Zealand White female rabbits with a GST-Abi-2 fusion protein or with a peptide corresponding to the amino terminus of Abi-2. Anti-Abl polyclonal antibodies and a mouse monoclonal antibody to Abl were described previously
(Konopka et al. 1984; Pendergast et al. 1991b). Antibodies against Ras GAP were obtained from Drs. R. Clark and F. McCormick. Monoclonal antibody against HA (12CA5) was purchased from Boehringer Mannheim. Monoclonal antibody against phosphotyrosine (PY69) was obtained from ICN Biochemicals, Inc.

\section{Plasmid constructions}

A cDNA fragment encoding the c-Abl SH3 domain (amino acids 47-147) was excised from pGEX3X/929-1029|P210[SH3] (Pendergast et al. 1991b) by BamHI-AatII restriction enzyme digestion and subcloned in-frame into pPC62 lobtained from P.M. Chevray / (Chevray and Nathans 1992). The resultant plasmid, designated $\mathrm{pPC} 60 / \mathrm{ablSH} 3$, directs the synthesis of a fusion protein containing the Gal4 DNA-binding domain and the SH3 domain of $\mathrm{c}-\mathrm{Abl}$ when expressed in yeast.

The pGEM vector (Promega) was used for in vitro transcription/translation of $a b i-2, c-a b l$, and their respective deletion mutants. The entire $a b i$-2-coding sequence was subcloned into the pGEM vector at the BamHI site. This plasmid, designated pGEM/abi-2, was subsequently digested with StuI to remove the sequence encoding amino acids 244-401 from $a b i-2$ and ligated to generate pGEM/abi-2 $\triangle 244-401$. To generate the SH3 domain deletion of $\mathrm{Abi}-2$, the DNA sequence encoding amino acids $161-321$ of Abi-2 was amplified by polymerase chain reaction (PCR). The PCR-generated cDNA fragment was digested with KpnI-HindIII and subcloned into pGEM/abi-2 at the KpnI and HindIII sites. The resultant plasmid was designated pGEM/ $a b i-2 \Delta S H 3$.

To express abi-2 in mammalian cells, a modified pCGN expression vector (Tanaka and Herr 1990) was used. The entire coding sequence of $a b i-2$ was subcloned in-frame into pCGN at the BamHI site downstream of the sequence encoding the hemagglutinin (HA) tag. The resultant plasmid pCGN/abi-2, under the control of the cytomegalovirus (CMV) promoter, directs the synthesis of Abi-2 with an HA tag fused at its amino terminus. Construction of pCGN/abi-2 $\Delta 1-100$ was performed by cutting the pGEM/abi-2 plasmid with $\mathrm{XbaI}$ and adding a $\mathrm{BamHI}$ linker to the $5^{\prime}$ end of $a b i-2$. The cDNA fragment with a $5^{\prime}$ deletion was then subcloned in-frame into the pCGN vector. To create pCGN/abi-2 $\Delta 1-157$, the pGEM/abi-2 plasmid was cut with KpnI, and following addition of a BamHI linker at the $5^{\prime}$, the BamHI cDNA fragment of $a b i-2$ was subcloned into pCGN. The plasmid pCGN/abi-2 $\Delta 158-243$ was created by an internal deletion of pGEM/abi-2 at the KpnI and StuI sites and subcloning of the deleted $a b i-2$ DNA into pCGN.

$\mathrm{pGEM} / \mathrm{c}-a b l$ and pGEM/abl $\triangle S H 3$ were constructed as described previously (Pendergast et al. 1991a). To generate carboxy-terminal deletion mutants of c-Abl a PCR-directed mutagenesis strategy was employed as described (Dai et al. 1992). The resultant plasmids, designated pGEM/abl $\Delta S H 3 \Delta 544-601$ and pGEM/abl $\Delta S H 3 \Delta 544-637$, respectively, bear double deletion of sequences encoding both $\mathrm{SH} 3$ and carboxy-terminal amino acids as indicated.

The pGEX $3 \mathrm{X}$ vector (Pharmacia) was used to express a GSTAbi-2 fusion protein. The entire coding sequence of $a b i-2$ was subcloned in-frame into pGEX $3 \mathrm{X}$ at the BamHI site, and the plasmid created was designated pGEX/abi-2. cDNA fragments encoding the $\mathrm{SH} 3$ and $\mathrm{SH} 2$ domains of c-Abl were subcloned in-frame into pGEX 3X as described (Pendergast et al. 1991b). cDNA fragments encoding Abl carboxy-terminal amino acids 593-1149, 593-730, and 731-1149 were excised from pGEM/c$a b l$ by appropriate restriction enzyme digestions and subcloned in-frame into pGEX $3 \mathrm{X}$. These cDNA fragments of c-abl, together with the full-length c- $a b l$ and c- $a b l \Delta S H 3$, were also sub- 
cloned in-frame into pAS-CYH2 (obtained from S. Elledge) (Harper et al. 1993) for testing the interaction by the yeast twohybrid system.

\section{Yeast two-hybrid screen}

The yeast two-hybrid system was employed to screen a human lymphocyte cDNA library as described (Durfee et al. 1993). The bait plasmid pPC60/ablSH3 was cotransformed with the cDNA library into yeast strain Y190 (Harper et al. 1993). Transformants $\left(4 \times 10^{5}\right)$ were screened for $l a c Z$ reporter gene expression by a filter lift assay (Durfee et al. 1993). Colonies that turned blue in $4 \mathrm{hr}$ were replicated onto a minus tryptophan, leucine, and histidine plate containing $25 \mathrm{~mm} 3-\mathrm{AT}$ and grown at $30^{\circ} \mathrm{C}$ for 3 days. Total DNA was isolated from the colonies that grew and used to transform the DH5 $\alpha$ bacterial strain. Plasmid DNA was isolated from ampicillin-resistant colonies and tested for bait-dependent reporter gene expression by retransforming back into yeast strain Y190 with pAS-CYH plasmid alone or bait plasmid pPC60/ablSH3. cDNAs that provided bait-dependent lacZ gene activation were subcloned into pBSK and subjected to dideoxy chain termination sequencing. PCR amplification of the abi-2 $5^{\prime}$-untranslated sequence was performed using the human lymphocyte cDNA library as template. Amplified cDNA fragments were subcloned into pBSK. Plasmid DNA from three independent colonies was prepared and sequenced. All three colonies contained cDNA inserts that represent the 5'-untranslated sequence of $a b i-2$. Sequence analysis was performed with the Genetics Computer Group program (Pearson and Lipman 1988). FASTA searches for homologous sequences were performed against the SwissProt, PirProtein, and GenBank data libraries. The accession number of the GenBank data base for the human abi-2 (previously aip-1) cDNA sequence reported in this paper is U23435.

\section{In vitro transcription and translation}

In vitro transcription/translation was performed using the SP6 in vitro transcription / translation kit (Promega) according to manufacturer's specifications. The reaction was incubated at $30^{\circ} \mathrm{C}$ for $2 \mathrm{hr}$, and in vitro-translated protein products were analyzed directly by SDS-PAGE or subjected to immunoprecipitation/binding assay prior to SDS-PAGE as indicated in text.

\section{Binding assays}

Radiolabeled proteins from whole-cell lysates or translated in vitro in reticulocyte lysates were incubated with GST or GST fusion proteins attached to glutathione-Sepharose beads as described previously (Pendergast et al. 1993). Bound proteins were analyzed by SDS-PAGE.

\section{Immunoblotting and in vitro kinase assay}

Immunoblotting was performed as described (Pendergast et al. 1993). Immunoreactive proteins were visualized by the enhanced chemiluminescence (ECL) detection system (Amersham) according to manufacturer's specifications. In vitro kinase assays were performed as described (Pendergast et al. 1993). Phosphorylation was carried out in the presence of $\left[\gamma^{-32} \mathrm{P}\right]$ ATP and $\mathrm{MnCl}_{2}$ for $30 \mathrm{~min}$ at $30^{\circ} \mathrm{C}$.

\section{Retrovirus infections and transformation assays}

Helper-free retroviral stocks were prepared by transient hyperexpression in Bosc 23 cells as described previously (Muller et al.
1991; Pear et al. 1993). Infection of NIH-3T3 fibroblasts with the indicated retroviruses was performed using polybrene as described previously (Muller et al. 1991). Following a 4-hr infection period, the cells were placed in fresh medium (DMEM $+10 \%$ FCS) and cultured for $21 / 2$ days before selection with G418. Cells were selected for 22 days. Western blot analysis was performed on cell populations at $21 / 2$ days postinfection and after 22 days of G418 selection. Cell transformation was quantitated by growth in soft agar as described previously (Muller et al. 1991). The cells $\left(1 \times 10^{4}\right)$ were plated per 6-cm dish in duplicate. Agar colonies with a diameter of $>0.5 \mathrm{~mm}$ were counted $\sim 2$ weeks after plating the cells.

\section{Acknowledgments}

We thank Dr. S. Elledge for kindly providing the yeast twohybrid system and human lymphocyte cDNA library, and Dr. S. Goff for sharing information before publication. We also thank Drs. M. Grove and X.F. Wang for critical reading of the manuscript and valuable discussions. This work was supported by National Cancer Institute grant CA61033 to A.M.P. Z.D. is a Fellow of the Leukemia Society of America. A.M.P. is a Whitehead Scholar and a Scholar of the Leukemia Society of America.

The publication costs of this article were defrayed in part by payment of page charges. This article must therefore be hereby marked "advertisement" in accordance with 18 USC section 1734 solely to indicate this fact.

\section{Note added in proof}

The sequence data for Abi- 2 has been submitted to the GenBank data library under accession number U23435.

\section{References}

Bergold, P.J., J.A. Blumenthal, E. D'Andrea, H.W. Snyder, L. Lederman, A. Silverstone, H. Nguyen, and P. Besmer. 1987. Nucleic acid sequence and oncogenic properties of the $\mathrm{HZ2}$ feline sarcoma virus v-abl insert. I. Virol. 61: 1193-1202.

Caracciolo, D., M. Valtieri, D. Venturelli, C. Peschle, A.M. Gewirtz, and B. Calabretta. 1989. Lineage-specific requirement of c-abl function in normal hematopoiesis. Science 245: $1107-1110$.

Chevray, P.M. and D. Nathans. 1992. Protein interaction cloning in yeast: Identification of mammalian proteins that react with the leucine zipper of Jun. Proc. Natl. Acad. Sci. 89: 5789-5793.

Cicchetti, P., B.J. Mayer, G. Thiel, and D. Baltimore. 1992. Identification of a protein that binds to the $\mathrm{SH} 3$ region of $\mathrm{Abl}$ and is similar to Bcr and GAP-rho. Science 257: 803-806.

Cohen, G.B., R. Ren, and D. Baltimore. 1995. Modular binding domains in signal transduction proteins. Cell 80: 237-248.

Dai, Z., A.D. Stiles, B. Moats-Staats, J.J. Van Wyk, and A.J. D'Ercole. 1992. Secretion of insulin-like growth factor-I (IGF-I) and its interaction with cell surface type I IGF receptors is the dominant mechanism of IGF-I's autocrine actions. $I$. Biol. Chem. 267: 19565-19570.

Darnell, J.E. Jr., I.M. Kerr, and G.R. Stark. 1994. Jak-STAT pathways and transcriptional activation in response to IFNs and other extracellular signaling proteins. Science 264: 14151421.

Durfee, T., K. Becherer, P.L. Chen, S.H. Yeh, Y. Yang, A.E. Kilburn, W.H. Lee, and S.J. Elledge. 1993. The retinoblastoma protein associates with the protein phosphatase type 1 catalytic subunit. Genes \& Dev. 7: 555-569. 
Duyster, J., R. Baskaran, and J.Y.J. Wang. 1995. Src homology 2 domain as a specificity determinant in the c-Abl-mediated tyrosine phosphorylation of the RNA polymerase II carboxyl-terminal repeated domain. Proc. Natl. Acad. Sci. 92: 1555-1559.

Feller, S.M., B. Knudsen, and H. Hanafusa. 1994a. c-Abl kinase regulates the protein binding activity of c-Crk. EMBO $/$. 13: 2341-2351.

Feller, S.M., R. Ren, H. Hanafusa, and D. Baltimore. 1994b. SH2 and $\mathrm{SH} 3$ domains as molecular adhesives: the interactions of Crk and Abl. Trends Biochem. Sci. 19: 453-458.

Fields, S. and O. Song. 1989. A novel genetic system to detect protein-protein interactions. Nature 340: 245-246.

Franz, W.M., P. Berger, and J.Y.J. Wang. 1989. Deletion of an $\mathrm{N}$-terminal regulatory domain of the c-abl tyrosine kinase activates its oncogenic potential. EMBO /. 8: 137-147.

Fukamachi, H., N. Yamada, T. Miura, T. Kato, M. Ishikawa, E. Gulbins, A. Altman, Y. Kawakami, and T. Kawakami. 1994. Identification of a protein, SPY75, with repetitive helix-turnhelix motifs and an SH3 domain as a major substrate for protein tyrosine kinase(s) activated by FceRI cross-linking. I. Immunol. 152: 642-652.

Gertler, F.B., A.R. Comer, J.-L. Juang, S.M. Ahern, M.J. Clark, E.C. Liebl, and F.M. Hoffmann. 1995. enabled, a dosage-sensitive suppressor of mutations in Drosophila Abl tyrosine kinase, encodes an Abl substrate with $\mathrm{SH} 3$ domain-binding properties. Genes \& Dev. 9: 521-533.

Goff, S.P., E. Gilboa, O.N. Witte, and D. Baltimore. 1980. Structure of the Abelson murine leukemia virus genome and the homologous cellular gene: studies with cloned viral DNA. Cell 22: 777-785.

Goga, A., J. McLaughlin, A.M. Pendergast, K. Parmar, A. Muller, N. Rosenberg, and O.N. Witte. 1993. Oncogenic activation of c-ABL by mutation within its last exon. Mol. Cell. Biol. 13: 4967-4975.

Harper, J.W., G.R. Adami, N. Wei, K. Keyomarsi, and S.J. Elledge. 1993. The p21 Cdk-interacting protein Cip1 is a potent inhibitor of G1 cyclin-dependent kinases. Cell 75: 805-816.

Jackson, P. and D. Baltimore. 1989. N-terminal mutations activate the leukemogenic potential of the myristoylated form of c-abl. EMBO J. 8: 449-456.

Jackson, P., D. Baltimore, and D. Picard. 1993. Hormone-conditional transformation by fusion proteins of c-Abl and its transforming variants. EMBO J. 12: 2809-2819.

Kemp, B.E. and R.B. Pearson. 1990. Protein kinase recognition sequence motifs. Trends Biochem. Sci. 15: 342-346.

Kipreos, E.T. and J.Y.J. Wang. 1990. Differential phosphorylation of c-Abl in cell cycle determined by cdc2 kinase and phosphatase activity. Science 248: 217-220.

1992. Cell cycle-regulated binding of c-Abl tyrosine kinase to DNA. Science 256: 382-385.

Kitamura, D., H. Kaneko, Y. Miyagoe, T. Ariyasu, and T. Watanabe. 1989. Isolation and characterization of a novel human gene expressed specifically in the cells of hematopoietic lineage. Nucleic Acids Res. 17: 9367-9379.

Konopka, J.B., S.M. Watanabe, and O.N. Witte. 1984. An alteration of human c-abl protein in K562 leukemia cells unmasks associated tyrosine kinase activity. Cell 37: 10351042.

Kurzrock, R., J.U. Gutterman, and M. Talpaz. 1988. The molecular genetics of Philadelphia chromosome-positive leukemias. New Engl. I. Med. 319: 990-998.

Mayer, B.J. and D. Baltimore. 1994. Mutagenic analysis of the roles of $\mathrm{SH} 2$ and $\mathrm{SH} 3$ domains in regulation of the Abl tyrosine kinase. Mol. Cell. Biol. 14: 2883-2894.
Mayer, B.J., P.K. Jackson, R.A. Van Etten, and D. Baltimore. 1992. Point mutations in the abl SH2 domain coordinately impair phosphotyrosine binding in vitro and transforming activity in vivo. Mol. Cell. Biol. 12: 609-618.

Mayer, B.J., H. Hirai, and R. Sakai. 1995. Evidence that SH2 domains promote processive phosphorylation by protein-tyrosine kinases. Curr. Biol. 5: 296-305.

McWhirter, J.R. and J.Y.J. Wang. 1993. An actin-binding function contributes to transformation by the Bcr-Abl oncoprotein of Philadelphia chromosome-positive human leukemias. EMBO /. 12: 1533-1546.

Moreno, S. and P. Nurse. 1990. Substrates for p34cdc2: In vivo veritas? Cell 61: 549-551.

Muller, A.J., J.C. Young, A.M. Pendergast, M. Pondel, N.R. Landau, D.R. Littman, and O.N. Witte. 1991. BCR first exon sequences specifically activate the $\mathrm{BCR} / \mathrm{ABL}$ tyrosine $\mathrm{ki}$ nase oncogene of Philadelphia chromosome-positive human leukemias. Mol. Cell. Biol. 11: 1785-1792.

Pabo, C.O. and R.T. Sauer. 1992. Transcription factors: Structural families and principles of DNA recognition. Annu. Rev. Biochem. 61: 1053-1095.

Pawson, T. 1995. Protein modules and signalling networks. $\mathrm{Na}$ ture 373: 573-580.

Pear, W.S., G.P. Nolan, M.L. Scott, and D. Baltimore. 1993. Production of high-titer helper-free retroviruses by transient transfection. Proc. Natl. Acad. Sci. 90: 8392-8396.

Pearson, W.R. and D.J. Lipman. 1988. Improved tools for biological sequence comparison. Proc. Natl. Acad. Sci. 85: 2444-2448.

Pendergast, A.M., J.A. Traugh, and O.N. Witte. 1987. Normal cellular and transformation-associated abl proteins share common sites for protein kinase C phosphorylation. Mol. Cell. Biol. 7: 4280-4289.

Pendergast, A.M., A.J. Muller, M.H. Havlik, R. Clark, F. McCormick, and O.N. Witte. 1991a. Evidence for regulation of the human ABL tyrosine kinase by a cellular inhibitor. Proc. Natl. Acad. Sci. 88: 5927-5931.

Pendergast, A.M., A.J. Muller, M.H. Havlik, Y. Maru, and O.N. Witte. 1991b. BCR sequences essential for transformation by the $\mathrm{BCR}-\mathrm{ABL}$ oncogene bind to the $\mathrm{ABL} \mathrm{SH} 2$ regulatory domain in a non-phosphotyrosine-dependent manner. Cell 66: $161-171$.

Pendergast, A.M., L.A. Quilliam, L.D. Cripe, C.H. Bassing, Z. Dai, N. Li, A. Batzer, K.M. Rabun, C.J. Der, J. Schlessinger, and M.L. Gishizky. 1993. BCR-ABL-induced oncogenesis is mediated by direct interaction with the $\mathrm{SH} 2$ domain of the GRB-2 adaptor protein. Cell 75: 175-185.

Reddy, B.A., M. Kloc, and L.D. Etkin. 1992. The cloning and characterization of a localized maternal transcript in Xenopus laevis whose zygotic counterpart is detected in the CNS. Mech. Dev. 39: 143-150.

Ren, R., B.J. Mayer, P. Cicchetti, and D. Baltimore. 1993. Identification of a ten-amino acid proline-rich $\mathrm{SH} 3$ binding site. Science 259: 1157-1161.

Ren, R., Z. S. Ye, and D. Baltimore. 1994. Abl protein-tyrosine kinase selects the Crk adapter as a substrate using SH3-binding sites. Genes \& Dev. 8: 783-795.

Renshaw, M.W., E.T. Kipreos, M.R. Albrecht, and J.Y.J. Wang. 1992. Oncogenic v-Abl tyrosine kinase can inhibit or stimulate growth, depending on the cell context. EMBO $\mathrm{J}$. 11: 3941-3951.

Rickles, R.J., M.C. Botfield, Z. Weng, J.A. Taylor, O.M. Green, J.S. Brugge, and M.J. Zoller. 1994. Identification of Src, Fyn, Lyn, PI3K and Abl SH3 domain ligands using phage display libraries. EMBO J. 13: 5598-5604.

Rogers, S., R. Wells, and M. Rechsteiner. 1986. Amino acid se- 
quences common to rapidly degraded proteins: The PEST hypothesis. Science 234: 364-368.

Rushlow, C., H. Doyle, T. Hoey, and M. Levine. 1987. Molecular characterization of the zerknullt region of the Antennapedia gene complex in Drosophila. Genes \& Dev. 1: 12681279.

Sawyers, C.L., J. McLaughlin, A. Goga, M. Havlik, and O.N. Witte. 1994. The nuclear tyrosine kinase c-Abl negatively regulates cell growth. Cell 77: 121-131.

Schwartzberg, P.L., A.M. Stall, J.D. Hardin, K.S. Bowdish, T. Humaran, S. Boast, M.L. Harbison, E.J. Robertson, and S.P. Goff. 1991. Mice homozygous for the ablml mutation show poor viability and depletion of selected $B$ and $T$ cell populations. Cell 65: 1165-1175.

Scott, M.P., J.W. Tamkun, and G.W. Hartzell. 1989. The structure and function of the homeodomain. Biochem. Biophys. Acta 989: 25-48.

Shi, Y., K. Alin, and S.P. Goff. 1995. Abl-interactor-1, a novel SH3 protein binding to the C-terminal portion of the Abl protein, suppresses v-abl transforming activity. Genes \& Dev. (this issue).

Songyang, Z., K.L. Carraway III, M.J. Eck, S.C. Harrison, R.A. Feldman, M. Mohammadl, J. Schlessinger, S.R. Hubbard, D.P. Smith, C. Eng, M.J. Lorenzo, B.A. Ponder, B.J. Mayer, and L.C. Cantley. 1995. Catalytic specificity of protein-tyrosine kinases is critical for selective signalling. Nature 373: $536-539$.

Takemoto, Y., M. Furuta, X.-K. Li, W.J. Strong-Sparks, and Y. Hashimoto. 1995. LckBP1, a proline-rich protein expressed in haematopoietic lineage cells, directly associates with the SH3 domain of protein tyrosine kinase p56 $6^{\text {lck }}$. EMBO $J$. 14: 3403-3414.

Tanaka, M. and W. Herr. 1990. Differential transcriptional activation by Oct-1 and Oct-2: interdependent activation domains induce Oct-2 phosphorylation. Cell 60: 375-386.

Tanaka, M., W.M. Clouston, and W. Herr. 1994. The Oct-2 glutamine-rich and proline-rich activation domain can synergize with each other or duplicates of themselves to activate transcription. Mol. Cell. Biol. 14: 6046-6055.

Trahey, M., G. Wong, R. Halenbeck, B. Rubinfeld, G.A. Martin, M. Ladner, C.M. Long, W.J. Crosier, K. Watt, K. Koths, and F. McCormick. 1988. Molecular cloning of two types of GAP complementary DNA from human placenta. Science 242: $1697-1700$.

Tybulewicz, V.L., C.E. Crawford, P.K. Jackson, R.T. Bronson, and R.C. Mulligan. 1991. Neonatal lethality and lymphopenia in mice with a homozygous disruption of the c- $a b l$ protooncogene. Cell 65: 1153-1163.

Van Etten, R.A., P. Jackson, and D. Baltimore. 1989. The mouse type IV c-abl gene product is a nuclear protein, and activation of transforming ability is associated with cytoplasmic localization. Cell 58: 669-678.

Van Etten, R.A., P.K. Jackson, D. Baltimore, M.C. Sanders, P.T. Matsudaira, and P.A. Janmey. 1994. The $\mathrm{COOH}$ terminus of the c-Abl tyrosine kinase contains distinct F- and G-actin binding domains with bundling activity. J. Cell. Biol. 124: 325-340.

Wang, J.Y.J. 1993. Abl tyrosine kinase in signal transduction and cell-cycle regulation. Curr. Opin. Genet. Dev. 3: 35-43.

Wang, J.Y.J., F. Ledley, S. Goff, R. Lee, Y. Groner, and D. Baltimore. 1984. The mouse c-abl locus: molecular cloning and characterization. Cell 36: 349-356.

Welch, P.J. and J.Y.J. Wang. 1993. A C-terminal protein-binding domain in the retinoblastoma protein regulates nuclear c-Abl tyrosine kinase in the cell cycle. Cell 75: 779-790.

Wetzler, M., M. Talpaz, R.A. Van Etten, C. Hirsh-Ginsberg, M.
Beran, and R. Kurzrock. 1993. Subcellular localization of Bcr, $\mathrm{Abl}$, and Bcr-Abl proteins in normal and leukemic cells and correlation of expression with myeloid differentiation. J. Clin. Invest. 92: 1925-1939.

Wu, H., A.B. Reynolds, S.B. Kanner, R.R. Vines, and J.T. Parsons. 1991. Identification and characterization of a novel cytoskeleton-associated pp60src substrate. Mol. Cell. Biol. 11: 5113-5124.

Yamanashi, Y., M. Okada, T. Semba, T. Yamori, H. Umemori, S. Tsunasawa, K. Toyoshima, D. Kitamura, T. Watanabe, and T. Yamamoto. 1993. Identification of HS1 protein as a major substrate of protein-tyrosine kinase(s) upon B-cell antigen receptor-mediated signaling. Proc. Natl. Acad. Sci. 90: 3631-3635.

Ziegler, S.F., C.A. Whitlock, S.P. Goff, A. Gifford, and O.N. Witte. 1981. Lethal effect of the Abelson murine leukemia virus transforming gene product. Cell 27: 477-486. 


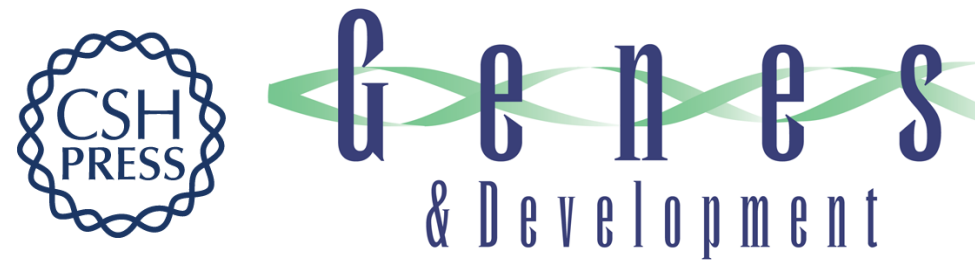

\section{Abi-2, a novel SH3-containing protein interacts with the c-AbI tyrosine kinase and modulates c-Abl transforming activity.}

Z Dai and A M Pendergast

Genes Dev. 1995, 9:

Access the most recent version at doi:10.1101/gad.9.21.2569

References This article cites 65 articles, 29 of which can be accessed free at:

http://genesdev.cshlp.org/content/9/21/2569.full.html\#ref-list-1

License

Email Alerting

Service

Receive free email alerts when new articles cite this article - sign up in the box at the top right corner of the article or click here.

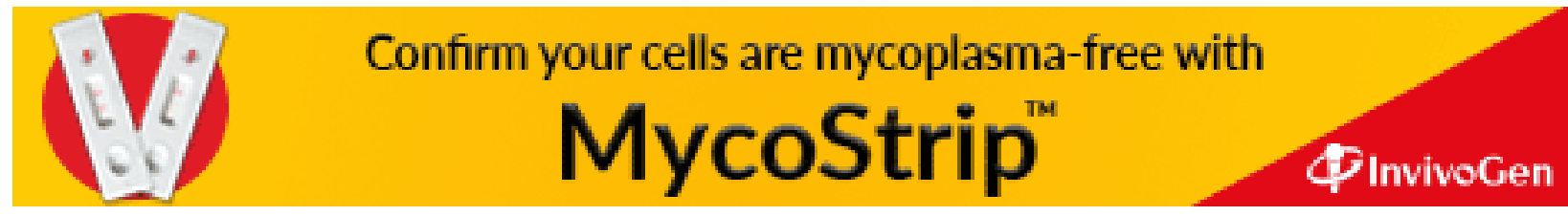

